\title{
Decision Making for Third Party Logistics Supplier Selection in Semiconductor Manufacturing Industry: A Nonadditive Fuzzy Integral Approach
}

\author{
Bang-Ning Hwang ${ }^{1}$ and Yung-Chi Shen ${ }^{2}$ \\ ${ }^{1}$ Department and Graduate Institute of Business Administration, National Yunlin University of Science \& Technology, \\ No. 123 University Road, Section 3, Douliou, Yunlin 64002, Taiwan \\ ${ }^{2}$ Department of BioBusiness Management, National Chiayi University, No. 580 Sinmin Road, Chiayi 600, Taiwan
}

Correspondence should be addressed to Yung-Chi Shen; syc@mail.ncyu.edu.tw

Received 22 August 2014; Accepted 6 January 2015

Academic Editor: Salvatore Alfonzetti

Copyright (C) 2015 B.-N. Hwang and Y.-C. Shen. This is an open access article distributed under the Creative Commons Attribution License, which permits unrestricted use, distribution, and reproduction in any medium, provided the original work is properly cited.

\begin{abstract}
The semiconductor industry has a unique vertically disintegrated structure that consists of various firms specializing in a narrow range of the value chain. To ensure manufacturing and logistics efficiency, the semiconductor manufacturers considerably rely on 3PL suppliers to achieve supply chain excellence. However, 3PL supplier selection is a complex decision-making process involving multiple selection criteria. The goal of this paper is to identify the key 3PL selection criteria by employing the nonadditive fuzzy integral approach. Unlike the traditional multicriterion decision-making (MCDM) methods which often assume independence among criteria and additive importance weights, the nonadditive fuzzy integral is a more effective approach to solve the dependency among criteria, vagueness in information, and essential fuzziness of human judgment. In this paper, we demonstrate an empirical case that employs the nonadditive fuzzy integral to evaluate the importance weight of selection criteria and choose the most appropriate 3PL supplier. The research result can become a valuable reference for manufacturing companies operating in comparable situations. Moreover, the systematic framework presented in this study can be easily extended to the analysis of other decision-making domains.
\end{abstract}

\section{Introduction}

The third-party logistics (3PL) involves the use of external companies to perform logistics functions traditionally managed by the manufacturing firms. Outsourcing isolated logistics activities, such as transportation and warehousing, to external service suppliers is not a new idea in the industry. Such outsourcing is based on simple make-or-buy considerations and choosing the cheapest alternative that meets preestablished service requirements [1]. However, due to the increasing supply chain complication, global competition, and customer demand for timeliness and flexibility of goods/services delivery, the role of 3PL has changed both in content and in complexity. While the previous driving forces for a firm to employ 3PL were to reduce operation costs and focus a firm's capital investment on its core competencies, the impetus today has a more strategic thrust: to increase market coverage, improve the level of service, and increase flexibility towards the changing requirements of customers [1-3]. Therefore, the decision of competent suppliers is of central importance for successful supply chain management [4-6].

3PL supplier selection is a complex analytical process essentially. A supplier selection problem usually involves more than one criterion, and criteria often conflict with each other [7]. Basically, the nature of the supplier selection is as a type of multicriterion decision-making (MCDM) problem based on the relative priority assigned to each selection criterion [8]. In MCDM, it is usually assumed that the criteria are independent; however, in real life, the available information in a decision-making process is usually uncertain, vague, or imprecise, and the criteria are not 
necessarily independent [7]. The traditional MCDM methods used to determine the importance of selection criteria often assume additive weights and independence among criteria. But an additive model is not always suitable due to the varying degrees of interactions among selection criteria [9]. On the contrary, the fuzzy measures do not need to assume the independence among criteria. The nonadditive fuzzy integral method, based on the fuzzy measures, has been developed to address the degree of interaction among diversified criteria and the vagueness existing in human subjective judgments $[10,11]$. Due to the advantage of better revealing the real environment, we employed the nonadditive fuzzy integral approach in this study to construct the 3PL supplier selection assessment process.

The remainder of this paper is organized as follows. Section 2 presents a review of the relevant literature of 3PL and its significance to the semiconductor manufacturing industry. Section 3 introduces the nonadditive fuzzy integral research method. Section 4 presents the empirical study that employs the research method to evaluate the importance weight of selection criteria and choose the most appropriate 3PL supplier. Finally, Section 5 discusses the research result and concludes the paper.

\section{Literature Review}

2.1. 3PL and 3PL Selection Criteria. 3PL functions encompass the entire logistics process or selected activities within that process [12]. Typical logistics activities performed by a 3PL supplier are warehousing, transportation, distribution, customer service, inventory, packaging, cross docking, logistics management, and reverse logistics $[13,14]$. The relationship between a 3PL supplier and its customers is that the first party is the client who purchases the logistics service and the second party is the client's customer(s); thus, the third party is the service supplier and acts as a middleman by taking title not to the products but to which logistics activities are outsourced [15].

Initially, 3PL services were relatively limited in scope [16]. Over time, 3PL suppliers began offering an increasingly integrated set of logistics activities and have become a mainstream in current business environment [17]. Most manufacturing companies are fond of 3PL suppliers, as they are alternatives with greater flexibility, cost saving, increased operational efficiency, better customer service, improved expertise, reengineering of logistics processes, and access to new technologies $[18,19]$. A meta-analysis evidenced that the employment of 3PL providers was in favor of a firm's performance [20]. Moreover, engaging logistics service of 3PL suppliers permits a manufacturing firm a better focus on its core businesses [21]. However, achieving a successful implementation of logistics outsourcing to $3 \mathrm{PL}$ is not an easy task [22]. Often-cited difficulties that concern a $3 \mathrm{PL}$ supplier's performance include a lack of understanding of client's supply chain needs, lack of adequate expertise in specific products and markets, inadequate description of services and service levels, lack of 3PL innovation, and lack of logistics cost awareness [22, 23]. Therefore, an efficient supplier management that begins with the identification of potential suppliers is prerequisite for successful logistics outsourcing.

Academia started research regarding the supplier selection of logistics services in the sixties [24, 25]. Among recent studies, one of the most comprehensive works is the one carried out by Ho et al. [8]. The study was based on the review of 78 papers related to supplier selection; the authors exhaustively addressed the issue of both qualitative and quantitative criteria that have to be considered when viable suppliers are to be ranked. Considering the nature of 3PL in particular, Coltman et al. [26] added selection criteria such as customer interaction, track-and-trace, service recovery, supply chain flexibility and capability, professionalism, proactive innovation, and relationship orientation. Some researchers examined the key selection factors for 3PL suppliers from particular perspectives. For example, Murphy and Poist [27] analyzed the key factors in a successful relationship from both supplier and user perspectives, whereas Gotzamani et al. [28] paid special attention to quality-related factors and deliberated the relationship between quality management and financial performance of 3PL suppliers. Chen et al. [29] employed transport cost, frequency of shipments, IT communication, quality performance, and order to shop time as 3PL selection criteria for apparel retailer industry.

As supplier selection is viewed to be a multicriterion decision-making process for most companies, some researchers have developed research frameworks that organize selection criteria according to a hierarchical structure. For example, Ku et al. [30] constructed a hierarchical framework to deal with the problem of global supplier selection. Wu and Tsai [31] applied 7 major criteria and 30 subcriteria to evaluate the suppliers for auto spare parts industry. Govindan et al. [32] listed 34 subcriteria and grouped them into seven criteria. Kang et al. [33] developed a multilevel hierarchy to support the supplier selection decision by considering five criteria and thirteen subcriteria. Vaidyanathan [34] proposed a 3PL evaluation framework that comprised six major criteria of IT, quality assurance, cost, services, performance, and intangibles. Sean [35] identified service-quality experience and service-quality credence as dual-role factors when selecting third-party reverse logistics suppliers. In conclusion, the 3PL supplier selection is based on multiple criteria, comprising both quantitative and qualitative criteria.

Incorporating many of these relevant criteria for the selection of a 3PL supplier, Table 1 summarizes most common 3PL selection criteria and groups them in six general categories, suggested by Vaidyanathan [34].

2.2. Semiconductor Manufacturing Industry in Taiwan. Taiwan's entire semiconductor industry is currently the fourth largest in the world, behind only the USA, Japan, and Korea. According to the publication IC Insight, Taiwan has become the largest semiconductor foundry manufacturer, second largest semiconductor designer, and the fourth largest semiconductor producer in the world. In contrast to the vertically integrated conglomerates dominating the industry in Korea and Japan, Taiwan's semiconductor industry has a unique vertically disintegrated structure that consists of many small-to-medium firms specializing in a narrow range 


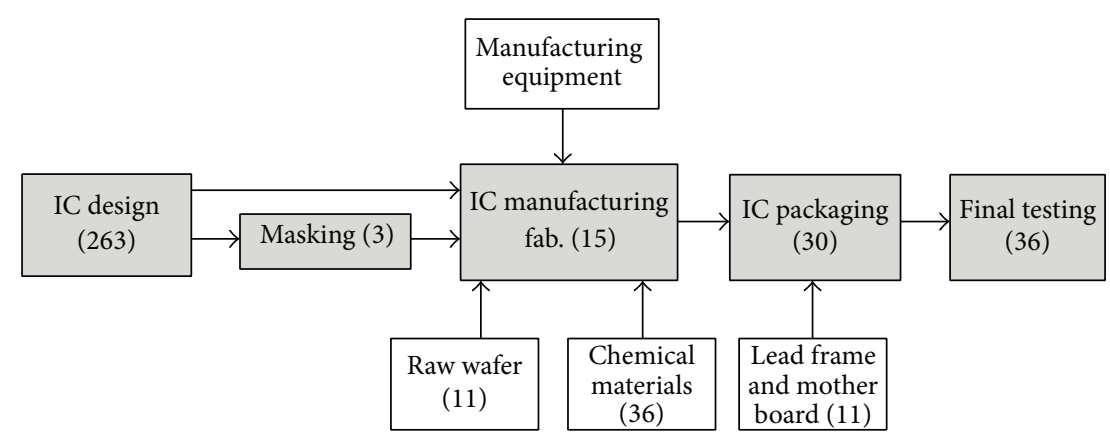

FIGURE 1: Semiconductor industry supply chain.

TABLE 1: 3PL selection criteria summary.

\begin{tabular}{|c|c|c|}
\hline Performance & $\begin{array}{l}\text { On-time delivery } \\
\text { Document Accuracy } \\
\text { Transportation safety } \\
\text { Shipment error rate }\end{array}$ & $\begin{array}{l}\text { Hertz and Alfredsson } \\
\text { [15]; Vaidyanathan [34]; } \\
\text { Göl and Çatay [38]; } \\
\text { Jharkharia and Shankar } \\
\text { [39]; Ordoobadi [40] }\end{array}$ \\
\hline Service & $\begin{array}{l}\text { Customer support } \\
\text { service } \\
\text { Problem-solving } \\
\text { capability } \\
\text { Value-added service }\end{array}$ & $\begin{array}{l}\text { Hertz and Alfredsson } \\
\text { [15]; Murphy and Poist } \\
\text { [27]; Vaidyanathan [34]; } \\
\text { Jharkharia and Shankar } \\
\text { [39]; Ordoobadi [40]; } \\
\text { Bottani and Rizzi [41]; } \\
\text { Sheen and Tai [42] }\end{array}$ \\
\hline Cost & $\begin{array}{l}\text { Continuous cost } \\
\text { reduction } \\
\text { Price }\end{array}$ & $\begin{array}{l}\text { Vaidyanathan [34]; } \\
\text { Bottani and Rizzi [41]; } \\
\text { Sheen and Tai [42]; } \\
\text { Daim et al. [43]; } \\
\text { Selviaridis and Spring } \\
{[44]}\end{array}$ \\
\hline $\begin{array}{l}\text { Quality } \\
\text { assurance }\end{array}$ & $\begin{array}{l}\text { Continuous } \\
\text { improvement } \\
\text { KPI tracking } \\
\text { ISO compliance }\end{array}$ & $\begin{array}{l}\text { Gotzamani et al. [28]; } \\
\text { Vaidyanathan [34]; Göl } \\
\text { and Çatay [38]; } \\
\text { Jharkharia and Shankar } \\
\text { [39]; Ordoobadi [40]; } \\
\text { Göl and Çatay [38] }\end{array}$ \\
\hline IT & $\begin{array}{l}\text { System stability } \\
\text { System scalability } \\
\text { Data security } \\
\text { Function coverage }\end{array}$ & $\begin{array}{l}\text { Vaidyanathan [34]; } \\
\text { Bottani and Rizzi [41]; } \\
\text { Daim et al. [43]; } \\
\text { McGinnis [45] }\end{array}$ \\
\hline Intangible & $\begin{array}{l}\text { Experience } \\
\text { Financial stability } \\
\text { Global scope } \\
\text { General reputation }\end{array}$ & $\begin{array}{l}\text { Murphy and Poist [27]; } \\
\text { Vaidyanathan [34]; Göl } \\
\text { and Çatay [38]; } \\
\text { Ordoobadi [40]; Bottani } \\
\text { and Rizzi [41]; Göl and } \\
\text { Çatay [38]; Daim et al. } \\
\text { [43]; Selviaridis and } \\
\text { Spring [44] }\end{array}$ \\
\hline
\end{tabular}

of the value chain, such as semiconductor integrated circuit (IC) design, mask production, and foundry manufacturing, packaging, and testing [36]. Figure 1 illustrates the five major segments that constitute the semiconductor industry supply chain. The number shown in the box represents the number of companies operating in that specific segment in Taiwan.
According to statistical data [37], there are more than 400 companies operating in the five major areas of the Taiwan semiconductor industry in 2010, among which there were 263 design houses, 3 mask makers, 15 fabrication companies, 66 packaging and testing companies, and 58 raw material suppliers. In a sense, Taiwan's semiconductor industry is organized as an industrial network, with a strong connection to each other as well as to the global semiconductor and downstream electronics markets.

As shown in Figure 1, the semiconductor manufacturing segment is located at the center of the supply chain and has the greatest number of logistics interactions with its upstream and downstream partners. To ensure manufacturing and logistics efficiency, the semiconductor manufacturers need to collaborate closely with their partners, both up and down the value chain [46]. Since logistics is not a core competency for semiconductor manufacturers, they outsource most of it to $3 \mathrm{PL}$ suppliers to create competitive resource bundles. It is without a doubt that advances in science and technology operating under the evolving industry vertical disintegration model have been the main contributors to Taiwan's semiconductor manufacturing industry success [36]; however, the effective global logistics performed by the 3PL suppliers, which seamlessly integrate the product and information flow among the significant number of semiconductor companies intra- and internationally in a timely manner, also plays a critical role in enabling global production networks.

\section{Research Method}

This section describes the background of the nonadditive fuzzy integral method and its suitability to our research, followed by a brief explanation of principle and operation process of the research method.

Basically, the nature of the supplier selection is as a type of multicriterion decision-making (MCDM) problem based on the relative priority assigned to each selection criterion [8]. A considerable number of decision models have been developed based on the MCDM theory, such as preference ranking organization method (PROMETHEE) [47], analytical hierarchy process (AHP) [48-50], analytic network process (ANP) [51], discrete choice analysis (DCA) [52], total cost ownership (TCO) [53], elimination et choice translating reality (ELECTRE) [54], and data envelopment 
analysis (DEA) [55, 56]. In MCDM, it is usually assumed that the criteria are independent and additive; hence the weighted average method is often applied to aggregate the importance weight of those criteria [57]. However, these assumptions are not always suitable in many real world applications [7, 57]. In the context of 3PL supplier selection, for example, the price charged by a supplier is dependent on its service quality, delivery lead time, and contract term and condition, which are all common criteria when considering supplier selection. Besides, the cost, risk, and quality of supplier are often interdependent for the supplier selection decision [58]. The ignorance of the interdependency effects could produce assessment bias and leads to ineffective decisions [59]. Moreover, most decision makers cannot give exact numerical values to assess the qualitative criteria such as supplier's flexibility, experience, and reputation. The judgments of the decision makers tend to be subjective and informal, which are difficult to define and interpret accurately [60]. In summary, the available information for most supplier selection decisions in real life is usually uncertain, vague, or imprecise, and the criteria are not necessarily independent [7]. To solve the abovementioned problems, Sugeno [61] proposed the fuzzy integral method which applied fuzzy measures [62] to deal with the problems of human subjective perception and uncertainty as well as to address the level of interdependency effects among criteria. The results of fuzzy measures can be further applied to assess the performance of interested alternatives [63]. The fuzzy integral method provides an alternative computational scheme for aggregating information [11]. Unlike the traditional additiveassessment methods not considering the interdependency effects between selection criteria [59] and adhering to the "additivity" property (i.e., the importance of two criteria in a probability framework can be nothing else than the sum of the importance of individual criteria), the fuzzy measure is more flexible in a way that it accepts greater or lower value than simply the sum of importance of multiple individual criteria. That is, the fuzzy integral method allows the modeling of interaction between criteria $[64,65]$. In fuzzy set theory, the linguistic variables are for expressing decision makers' vague and imprecise semantics. Linguistic variable is very useful in dealing with complex situations that are difficult to be reasonably described in conventional quantitative expressions [66, 67]. Applying the linguistic variables, the nonadditive fuzzy integral approach enables researchers to handle the vague and imprecise semantics and solve the interdependence among criteria to eliminate subjective judgment problems involved in a decision-making complex.

The nonadditive fuzzy integral method has been popularly applied in diverse fields including cost analysis $[68,69]$, location selection $[57,70,71]$, eco-tour plan selection [72, 73], performance evaluation [74-78], performance and risk measurement [79], operating model evaluation [80], supplier selection [81, 82], risk assessment [83], strategy development [84, 85], technology innovation [86], and data selection for hyperspectral image sensing [87]. In summary, due to the advantage of better revealing the real environment in

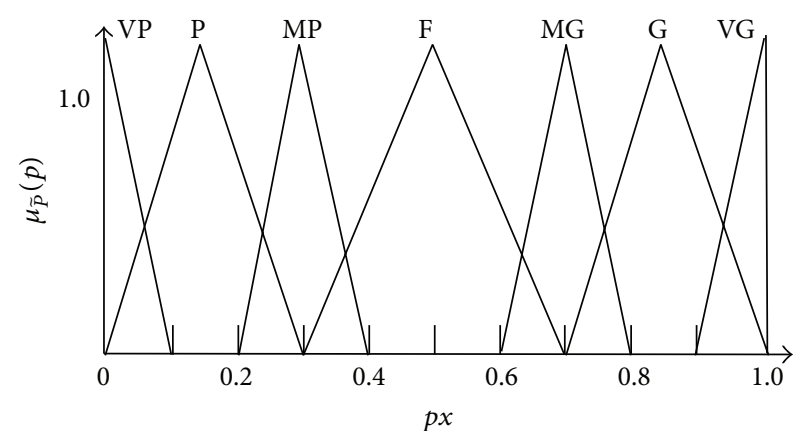

FIGURE 2: Membership function for importance degree and performance value.

a multicriterion decision-making complex, the nonadditive fuzzy integral approach is employed in this study.

The principle and operation process of the nonadditive fuzzy integral are described as follows.

\subsection{Step 1: Determine the Importance Degree of Decision} Factors. Based on the fuzzy logic, linguistic variables are used to determine the importance degree of decision factors. The concept of linguistic variable was presented by Zadeh $[66,67]$. A linguistic variable is a variable whose values are words or sentences in natural or artificial language. For example, "performance" is a linguistic variable; its values are very poor (VP), poor (P), median poor (MP), fair (F), median good (MG), good (G), and very good (VG). This study adopts triangular fuzzy numbers of seven intervals, that is, from very poor (VP) to very good (VG), to describe these linguistic importance terms expressed by decision makers. Their fuzzy numbers are defined as $(0.0,0.0,0.1),(0.0,0.15,0.3),(0.2,0.3$, $0.4),(0.3,0.5,0.7),(0.6,0.7,0.8),(0.7,0.85,1.0)$, and $(0.9,0.9$, $1.0)$, respectively. The fuzzy numbers for importance degree of decision factors are shown as in Figure 2.

Making a decision in a multicriterion situation, decision makers' perceptions of criteria vary in terms of the evaluations of linguistic variables with respect to importance weighting on decision factors. Given $m$ decision makers, the evaluated values of importance are expressed as $\widetilde{w}_{i}, i=$ $1,2, \ldots, m$. One way to integrate decision makers' options on importance weights that are expressed by linguistic variables can be done by applying the fuzzy arithmetic which was proposed by Dubois and Prade [80]. The aggregation of importance weights determined by $m$ decision makers is presented by three vertices of triangular fuzzy number with the following equation:

$$
\begin{aligned}
\overline{\widetilde{W}}_{i j} & =\left({ }_{L} \bar{w}_{i j},{ }_{M} \bar{w}_{i j}, R \bar{w}_{i j}\right) \\
& =\left(\frac{\left(\sum_{p=1}^{m} w_{i j}^{p}\right)}{m}, \frac{\left(\sum_{p=1}^{m} w_{i j}^{p}\right)}{m}, \frac{\left(\sum_{p=1}^{m} w_{i j}^{p}\right)}{m}\right),
\end{aligned}
$$

where $\overline{\widetilde{W}}_{i j}=\left({ }_{L} \bar{w}_{i j},{ }_{M} \bar{w}_{i j},{ }_{R} \bar{w}_{i j}\right)$ is triangular fuzzy numbers and their points on the left, middle, and right positions. ${ }_{L} \bar{w}_{i j}$, 
${ }_{M} \bar{w}_{i j}$, and ${ }_{R} \bar{w}_{i j}$ denote the importance of dimension $i$ and criterion $j$.

However, the fuzzy importance weights of decision factors need to be converted into crisp numbers for sequent utilization. Many defuzzification methods have been developed, including center of sum, center of gravity, mean of maxima, and $\alpha$-cut. The defuzzification method proposed by Chen and Klein [81] is a highly sensitive and effective approach. By using the Chen and Klein [81] defuzzying approach, the crisp value of importance weight can be obtained and further imported to fuzzy integral to aggregate the overall performance of alternatives. Chen and Klein [81] employed a method utilizing fuzzy subtraction of a referential rectangle, $\widetilde{R}$, from a fuzzy number, $\widetilde{X}$; the rectangle is derived by multiplying the height of the membership function of $\widetilde{X}$ by the distance between the two crisp maximizing and minimizing barriers. Here, $\widetilde{R}$ can be considered a fuzzy number. Fuzzy subtraction of the referential rectangle $\widetilde{R}$ from the fuzzy number $\widetilde{X}$ can be performed at level $\alpha_{i}$ as follows:

$$
\begin{aligned}
\widetilde{X}_{\alpha_{i}}\langle-\rangle \widetilde{R}=\left[l_{i}, r_{i}\right][-][c, d] & =\left[l_{i}-d, r_{i}-c\right], \\
i & =0,1,2, \ldots \infty,
\end{aligned}
$$

where $\langle-\rangle$ and $[-]$ represent fuzzy subtraction and interval subtraction operators, respectively, $l_{i}$ and $r_{i}$ denote the left and right loci of $\widetilde{R}$, and $c$ and $d$ are the left and right barriers, respectively. The defuzzification rating of the fuzzy number can be obtained with the following equation:

$$
D(\widetilde{X})=\frac{\sum_{i=0}^{n} r_{i}-c}{\sum_{i=1}^{n}\left(r_{i}-c\right)-\sum_{i=0}^{n}\left(l_{i}-d\right)}, \quad n \longrightarrow \infty,
$$

where $n$ denotes the number of $\alpha$-cuts; as $n$ approaches $\infty$, the sum is the measured area. In (3), $\sum_{i=1}^{n}\left(r_{i}-c\right)$ is positive, $\sum_{i=1}^{n}\left(l_{i}-d\right)$ is negative, and $0 \leq D(\widetilde{X}) \leq 1$ if $0 \leq x \leq 1$.

3.2. Step 2: Evaluate the Performance Values of Alternatives. To evaluate the performance value on a set of decision factors, the same fuzzy numbers of seven intervals, as presented in Figure 2, are applied. Similarly, the aggregation of $m$ decision makers' opinions on the performance of decision factors is obtained with the following equation:

$$
\begin{aligned}
\overline{\widetilde{P}}_{i j} & =\left({ }_{L} \bar{p}_{i j}, M \bar{p}_{i j},{ }_{R} \bar{p}_{i j}\right) \\
& =\left(\frac{\left(\sum_{p=1}^{m} p_{i j}^{p}\right)}{m}, \frac{\left(\sum_{p=1}^{m} p_{i j}^{p}\right)}{m}, \frac{\left(\sum_{p=1}^{m} p_{i j}^{p}\right)}{m}\right),
\end{aligned}
$$

where $\overline{\widetilde{P}}_{i j}=\left({ }_{L} \bar{p}_{i j},{ }_{M} \bar{P}_{i j},{ }_{R} \bar{p}_{i j}\right)$ is triangular fuzzy numbers and their points on the left, middle, and right positions. ${ }_{L} \bar{p}_{i j}$, ${ }_{M} \bar{p}_{i j}$, and ${ }_{R} \bar{p}_{i j}$ represent the overall average ratings of decision factors on aspect $i$ and criteria $j$ over $m$ decision makers. The same defuzzification approach developed by Chen and Klein [81] is adopted to convert the fuzzy performance values into crisp numbers for sequent fuzzy integral.
After obtaining the performance values on decision factors, we can aggregate the overall performance of alternatives and determine the degrees of importance for fuzzy decision factors. Fuzzy measure can be explicated as the subjective importance of a criterion during the evaluation process. Sugeno and Terano [82] incorporated the $\lambda$-additive axiom to simplify information accumulation. In fuzzy measure space $(\mathbf{X}, \beta, g)$, let $\lambda \in(-1, \infty)$. If $A \in \beta, B \in \beta, A \cap B=\phi$, then the fuzzy measure $g$ is $\lambda$-additive. This particular fuzzy measure is termed as $\lambda$-fuzzy measure because it has to satisfy $\lambda$ additively and is known as the Sugeno measure [61].

Assume that $\mathbf{X}=\left\{x_{1}, x_{2}, \ldots, x_{n}\right\}$ and $P(\mathbf{X})$ is the power set of $\mathbf{X}$; the set function $g: P(X) \rightarrow[0,1]$ is a fuzzy measure, which is nonadditive and preserves the following properties.

$\forall A, B \in \beta(\mathbf{X}), A \cap B=\phi$, and $g_{\lambda}(A \cup B)=g_{\lambda}(A)+$ $g_{\lambda}(B)+\lambda g_{\lambda}(A) g_{\lambda}(B)$ for $-1<\lambda<\infty$. To differentiate this measure from other fuzzy measures, $g_{\lambda}$ denotes $\lambda$-fuzzy measure. When $\lambda \neq 0$, the $\lambda$-fuzzy measure $g$ is nonadditive; otherwise, $\lambda=0$ means that the $\lambda$-fuzzy measure $g$ is additive and there is no interaction between decision factors [83]. Additionally, the $\lambda$-fuzzy measure of the finite set can be derived from fuzzy densities, as indicated in the following equation $[84,85]$ :

$$
\begin{aligned}
g_{\lambda} & \left(\left\{x_{1}, x_{2}, \ldots, x_{n}\right\}\right) \\
= & \sum_{i=1}^{n} g_{i}+\lambda \sum_{i_{1}=1}^{n-1} \sum_{i_{2}=i_{1}+1}^{n} g_{i_{1}} g_{i_{2}}+\cdots+\lambda^{n-1} g_{1} g_{2}, \ldots, g_{n} \\
= & \frac{1}{\lambda}\left|\prod_{i=1}^{n}\left(1+\lambda g_{i}\right)-1\right| \\
& \quad \text { for }-1<\lambda<\infty .
\end{aligned}
$$

Based on the boundary conditions in (1), $g_{\lambda}(\mathbf{X})=1, \lambda$ can be determined via the following equation:

$$
\lambda+1=\prod_{i=1}^{n}\left(1+\lambda g_{i}\right)
$$

In fuzzy measure space $(\mathbf{X}, \beta, g)$, let $h$ denote a measurable function from $\mathbf{X}$ to $[0,1]$. The fuzzy integral of $h$ over $A$ with respect to $g$ is then defined as

$$
\int_{A} h(x) d g=\sup _{\alpha \in[0,1]}\left[\alpha \wedge g\left(A \cap F_{\alpha}\right)\right]
$$

where $F_{\alpha}=\{x \mid h(x) \geq \alpha\}$ [9] and $A$ represents the domain of a fuzzy integral. When $A=X$, the fuzzy integral can be presented as $\int h d g$. For simplicity, consider a fuzzy measure $g$ of $(\mathbf{X}, P(\mathbf{X}))$ where $\mathbf{X}$ is a finite set. Let $h: \mathbf{X} \rightarrow[0,1]$ and assume, without loss of generality, that the function $h\left(x_{i}\right)$ is monotonically decreasing in $i$; for instance, $h\left(x_{1}\right) \geq h\left(x_{2}\right) \geq$ $\cdots \geq h\left(x_{n}\right)$. To ensure that the elements in $\mathbf{X}$ are renumbered, we get the following equation:

$$
\int h(x) g=\bigvee_{i=1}^{n}\left[h\left(x_{i}\right) \wedge g\left(H_{i}\right)\right]
$$


where $H_{i}=\left\{x_{1}, x_{2}, \ldots, x_{n}\right\}, i=1,2, \ldots, n$. In practice, $h$ can be regarded as a given alternative's performance on a particular decision factor, and $g$ represents the subjective importance weight of each decision factor. The nonadditive fuzzy integral of $h(x)$ with respect to $g$ gives the overall assessment of the attribute. To simplify the calculation, the same fuzzy measure of Choquet integral is expressed as follows:

$$
\begin{aligned}
(c) \int h d g= & h\left(x_{n}\right) g\left(H_{n}\right)+\left[h\left(x_{n-1}\right)-h\left(x_{n}\right)\right] g\left(H_{n-1}\right) \\
& +\cdots+\left[h\left(x_{1}\right)-h\left(x_{2}\right)\right] g\left(H_{1}\right) \\
= & h\left(x_{n}\right)\left[g\left(H_{n}\right)-g\left(H_{n-1}\right)\right] \\
& +h\left(x_{n-1}\right)\left[g\left(H_{n-1}\right)-g\left(H_{n-2}\right)\right] \\
& +\cdots+h\left(x_{1}\right) g\left(H_{1}\right),
\end{aligned}
$$

where $0 \leq h\left(x_{1}\right) \leq h\left(x_{2}\right) \leq \cdots \leq h\left(x_{n}\right) \leq 1, H_{1}=\left\{x_{1}\right\}$, and $H_{2}=\left\{x_{1}, x_{2}\right\}, \ldots, H_{n}=\left\{x_{1}, x_{2}, \ldots, x_{n}\right\}=\mathbf{X}$. In literature, the fuzzy integral defined by $\int h d g$ is termed a nonadditive fuzzy integral and denotes the overall performance of alternatives.

\section{Empirical Study in Semiconductor Manufacturing Industry}

An empirical study was conducted to identify the key 3PL selection criteria in the semiconductor manufacturing industry. Firstly, we constructed a decision hierarchy consisting of three levels of selection criteria, as described in Section 4.1. Next, we conducted a field survey within semiconductor manufacturing companies to obtain the importance degree of identified selection criteria in Section 4.2. Subsequently, we demonstrated how a company applied the obtained importance degree of identified selection criteria to select the most appropriate 3PL supplier from a series of alternatives in Section 4.3. The practice of the nonadditive fuzzy integral method is illustrated in Sections 4.2 and 4.3.

4.1. Define the Decision Hierarchy. Derived from the selection criteria summarized in Table 1, a three-level hierarchy of selection criteria comprising 6 criterion dimensions and 20 subcriteria was developed, as shown in Figure 3. The top level of the hierarchy, denoted by level 1 , represents the ultimate goal of the research, which is to identify the determinants of 3PL selection criteria. The next two levels contain the 6 evaluation criterion dimensions and 20 subcriteria, respectively.

The criteria listed in Figure 3 have both quantitative and qualitative variables and some of them have dependency relationship. For example, the criteria such as the shipment error rate $\left(x_{13}\right)$ or contract price $\left(x_{31}\right)$ are quantitative. Conversely, other criteria such as commitment of continuous improvement $\left(x_{43}\right)$ and general reputation $\left(x_{64}\right)$ are qualitative; therefore, their evaluation by most decision makers tends to be subjective and imprecise. The dependency relationship among criteria exists in a scene in which a 3PL supplier's shipment error rate would cause impacts to the contract price with its client, and, to a certain degree, a 3PL supplier's general reputation depends on its delivery performance, quality assurance, and problem-solving capability. To address the dependency among criteria, vagueness in information, and essential fuzziness of human judgment, the nonadditive fuzzy integral method is applied successively.

4.2. Determine the Importance Degree of Selection Criteria. In line with the developed three-level hierarchy of 3PL selection criteria, we designed a questionnaire complying with the fuzzy integral format. The convenient sampling technique was adopted in this study, due to the fact that it permitted researchers to survey qualified experts more easily. These questionnaires targeted managers and senior staff responsible for import/export, purchasing, warehousing, materials management, or logistics outsourcing in the semiconductor manufacturing industry. There were ten domain experts responding to the survey. The average length of respondents' work experience was more than 10 years.

In the nonadditive fuzzy integral method, the criteria weighting begins from the bottom level of decision hierarchy. In the hierarchical structure, every item comprises an answer to a question and the associated importance weight. For example, in this empirical study, the criterion dimension of performance would have four answered questions and associated importance weight values for its associated four subcriteria, that is, on-time delivery, transportation safety, shipment error rate, and document accuracy, respectively. During the survey process, the importance values of criteria were weighted by using the fuzzy number. In the beginning, the survey respondents evaluated the importance of selection criteria via a questionnaire. Their evaluation values were then converted into triangular fuzzy numbers by using linguistic variables as shown in Figure 2. Subsequently, the importance weights of selection criteria were calculated by aggregating survey respondents' evaluation values via (1). Finally, we could derive the importance weights by using (3); the result is shown in Table 2. As we can see in Table 2, the criterion dimension of performance has the highest rank, with a weight of 0.909 , followed by cost and service (both of them have the same importance weight of 0.769 ), then by quality assurance and intangible, with the same importance weight of 0.667 , and lastly by IT with the weight of 0.500 . Within each criterion dimension, the weights of belonging subcriteria indicate their importance ranking. For example, the subcriterion of document accuracy in the dimension of performance has the highest ranking $(0.877)$ followed by transportation safety $(0.867)$, shipment error rate $(0.833)$, and on-time delivery $(0.815)$.

4.3. Evaluate the Performance Values of Alternatives. Based on the importance weights of 3PL selection criteria obtained in Table 2, a major semiconductor manufacturing company in Taiwan conducted a group decision meeting of $3 \mathrm{PL}$ supplier selection. For confidentiality reasons, a fictitious name, Company $\mathrm{X}$, is used to represent the case company, one of the top 10 semiconductor manufacturing companies in the world. Company $\mathrm{X}$ has more than 10 manufacturing 


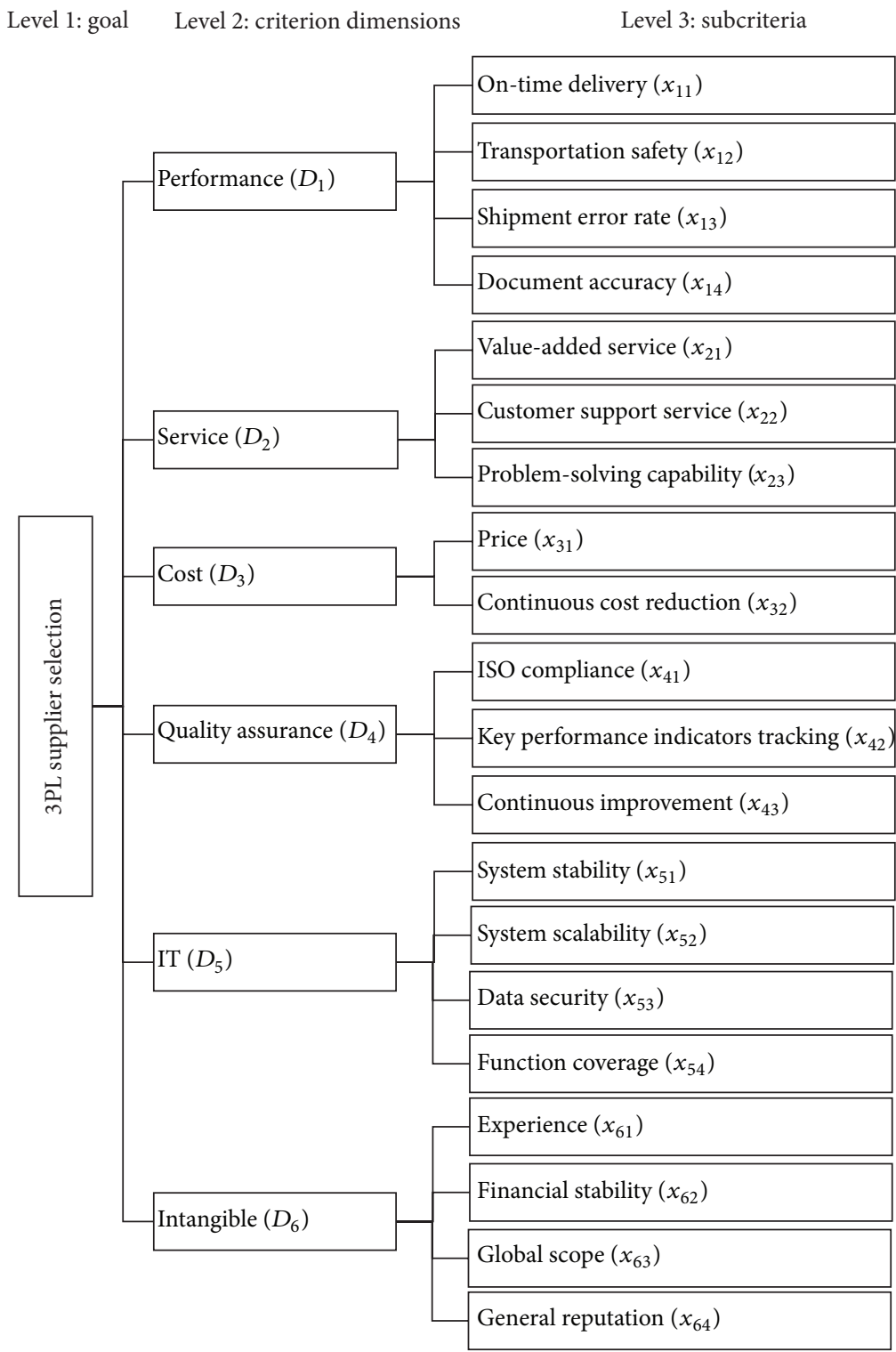

FIgURE 3: The hierarchy of 3PL provider selection.

plants in Taiwan, China, Singapore, and the USA. As of 2013, the company served more than 400 worldwide customers with more than 7,000 products manufacturing for a variety of electronic applications in computer, communication, and consumer markets. Four 3PL suppliers were considered for the study; they were all large operations with global networks of services: UPS, DHL, two distinguished American logistics companies, Nippon Express, a notable Japanese company, and Morrison, the largest 3PL supplier in Taiwan. We mask the identities of the four candidates by labelling them suppliers $\mathrm{A}, \mathrm{B}, \mathrm{C}$, and $\mathrm{D}$ with random sequence.

At the outset, the selection team members evaluated these alternatives' performance according to the selection criteria shown in Figure 3. With the performance results collected from the selection team, we then aggregated them as fuzzy performance values by using (4) and converted them into crisp numbers by using (3). The value $\lambda$ of each dimension was calculated by using (6) with corresponding measure density $g_{i}$, the importance weight of each subcriterion. Finally, we can get the Choquet integral value and $\lambda$-value for the overall performance of one alternative by using (9).

Table 3 shows the fuzzy measure and aggregated value for one of the 3PL suppliers, the supplier A. The 4th column, $g_{i}(\cdot)$, in Table 3, inherited from the last column in Table 2, presents the importance weights of subcriteria. The crisp performance value, $h(\cdot)$, the 3 rd column in Table 3 , shows the given 3PL suppliers' performance on each subcriterion. The $\lambda$-value of the 5 th column presents the fuzzy measure and the Choquet integral value $(c) \int h(\cdot) d g_{\lambda}$, the last column, represents the overall perceived performance of the selection team's perception on the entire selection criteria. As shown in Table 3, the criterion dimension $D_{2}$ has the highest 
TABLE 2: Weights of 6 criterion dimensions and 20 subcriteria.

\begin{tabular}{|c|c|c|c|}
\hline Dimension & Weight $\left(g_{i}(\cdot)\right)$ & Criterion & Weight $\left(g_{i}(\cdot)\right)$ \\
\hline \multirow{4}{*}{ Performance $\left(D_{1}\right)$} & \multirow{4}{*}{0.909} & On-time delivery $\left(x_{11}\right)$ & 0.815 \\
\hline & & Transportation safety $\left(x_{12}\right)$ & 0.867 \\
\hline & & Shipment error rate $\left(x_{13}\right)$ & 0.833 \\
\hline & & Document accuracy $\left(x_{14}\right)$ & 0.877 \\
\hline \multirow{3}{*}{ Service $\left(D_{2}\right)$} & \multirow{3}{*}{0.769} & Value-added service $\left(x_{21}\right)$ & 0.789 \\
\hline & & Customer support service $\left(x_{22}\right)$ & 0.714 \\
\hline & & Problem-solving capability $\left(x_{23}\right)$ & 0.838 \\
\hline \multirow{2}{*}{$\operatorname{Cost}\left(D_{3}\right)$} & \multirow{2}{*}{0.769} & Price $\left(x_{31}\right)$ & 0.794 \\
\hline & & Continuous cost reduction $\left(x_{32}\right)$ & 0.877 \\
\hline \multirow{3}{*}{ Quality assurance $\left(D_{4}\right)$} & \multirow{3}{*}{0.667} & ISO compliance $\left(x_{41}\right)$ & 0.762 \\
\hline & & Key performance indicators tracking $\left(x_{42}\right)$ & 0.805 \\
\hline & & Continuous improvement $\left(x_{43}\right)$ & 0.702 \\
\hline \multirow{4}{*}{$\operatorname{IT}\left(D_{5}\right)$} & \multirow{4}{*}{0.500} & System stability $\left(x_{51}\right)$ & 0.722 \\
\hline & & System scalability $\left(x_{52}\right)$ & 0.693 \\
\hline & & Data security $\left(x_{53}\right)$ & 0.779 \\
\hline & & Function coverage $\left(x_{54}\right)$ & 0.800 \\
\hline \multirow{4}{*}{ Intangible $\left(D_{6}\right)$} & \multirow{4}{*}{0.667} & Experience $\left(x_{61}\right)$ & 0.800 \\
\hline & & Financial stability $\left(x_{62}\right)$ & 0.742 \\
\hline & & Global scope $\left(x_{63}\right)$ & 0.726 \\
\hline & & General reputation $\left(x_{64}\right)$ & 0.752 \\
\hline
\end{tabular}

TABLE 3: Fuzzy measure and aggregated values for 3PL supplier A.

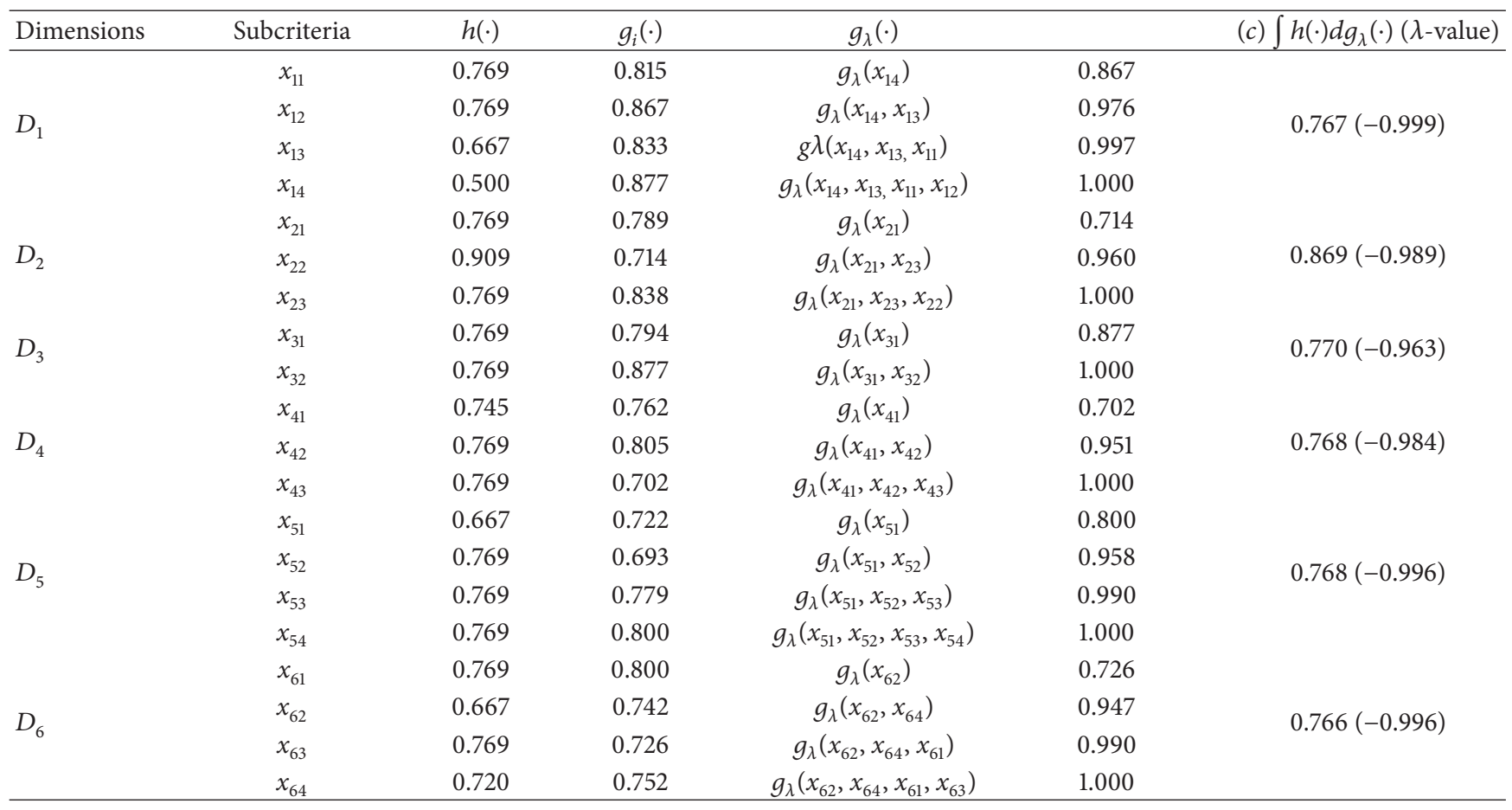

Choquet integral value of 0.869 among all the six dimensions, which indicates that supplier A performs best in the Service selection criterion dimension according to the judgment of the selection team. Moreover, the $\lambda$-value closing to -1 means the existence of complete dependent and mutual influence relationships among criteria.
The Choquet integral value of each individual criterion dimension can be further aggregated to determine the overall performance of supplier A. As shown in Table 4, the $h(\cdot)$ column, inherited from Table 3, is supplier A's performance on each criterion dimension, whereas the $g_{i}(\cdot)$ column, inherited from Table 2, is the importance weight of the six 
TABLE 4: Fuzzy measure and overall performance values for 3PL supplier A.

\begin{tabular}{ccccccc}
\hline 3PL supplier & Criterion group & $h(\cdot)$ & $g_{i}(\cdot)$ & $g_{\lambda}(\cdot)$ & $(c) \int h(\cdot) d g_{\lambda}(\cdot)(\lambda$-value $)$ \\
\hline & $D_{1}$ & 0.767 & 0.909 & $g_{\lambda}\left(D_{6}\right)$ & 0.769 & \\
& $D_{2}$ & 0.869 & 0.769 & $g_{\lambda}\left(D_{6}, D_{1}\right)$ & 0.980 & 0.994 \\
A & $D_{3}$ & 0.770 & 0.909 & $g_{\lambda}\left(D_{6}, D_{1}, D_{4}\right)$ & $0.947(-0.999)$ \\
& $D_{4}$ & 0.768 & 0.769 & $g_{\lambda}\left(D_{6}, D_{1}, D_{4}, D_{5}\right)$ & 1.000 & \\
& $D_{5}$ & 0.768 & 0.667 & $g_{\lambda}\left(D_{6}, D_{1}, D_{4}, D_{5}, D_{3}\right)$ & $g_{\lambda}\left(D_{6}, D_{1}, D_{4}, D_{5}, D_{3}, D_{2}\right)$ & 1.000 \\
\hline
\end{tabular}

TABLE 5: 3PL suppliers' performance values and rankings.

\begin{tabular}{lcc}
\hline 3PL supplier & Performance value & Ranking \\
\hline A & 0.847 & 3 \\
B & 0.892 & 1 \\
C & 0.885 & 2 \\
D & 0.832 & 4 \\
\hline
\end{tabular}

criterion dimensions. Applying (6) and (9), we can get the fuzzy measure $\lambda$-value of $g_{\lambda}(\cdot)$ and the Choquet integral value $(c) \int h(\cdot) d g_{\lambda}$, respectively. The Choquet integral value of 0.847 is the overall performance of supplier A.

Applying the same calculation process to the remaining three 3PL supplier alternatives, we could obtain their overall performance values, as shown in Table 5. The result shows that supplier $\mathrm{B}$ is the one with the highest performance value (0.892), followed by suppliers C (0.885), A (0.847), and D (0.832), respectively. Therefore, supplier B is the best choice with the considerations of the multiplicative effects of criteria and dimensions.

\section{Discussion and Conclusion}

Through the nonadditive fuzzy integral operation process aforementioned, we demonstrated how the importance degree of the 3PL supplier selection criteria was obtained and how the most appropriate 3PL supplier was determined from a series of alternatives. The results shown in Table 2 reveal that the criterion dimension of performance has the highest rank, with a weight of 0.909 , followed by cost $(0.769)$, service (0.769), quality assurance (0.667), intangible (0.667), and IT (0.500). The fact that all the top three criterion dimensions, namely, performance, cost, and service, have as high as more than 75 percent of importance weight indicates that a 3PL supplier that can deliver high-performance logistics functions, combined with thorough cost control capability and high-quality customer services, is appealing to the semiconductor manufacturing industry most. At the detailed-level, the document accuracy (0.877) ranks number 1 within 20 subcriteria. The justification of such high ranking is because the main documents required for contemporary international logistics include as many as 200 or more data elements that are keyed in multiple times by various parties [86]. Without accurate documentation, goods shipments could remain in customs' possession, which incurs high shipment error rates and thus jeopardizes on-time delivery. This interdependency relationship explains why document accuracy is ranked ahead of shipment error rate and ontime delivery in the performance dimension; that is, when the requirement of document accuracy is fulfilled, the results of shipment error and on-time delivery rates are improved accordingly.

3PL supplier selection is a complex analytical process and involves a wide range of quantitative and qualitative selection criteria. Within a multicriterion decision-making situation, decision criteria have to be defined and weighted, alternatives need to be evaluated, and finally best satisfying alternative could be identified. The information available for use in multicriterion decision-making complex is usually uncertain, vague, or imprecise, and the criteria are not necessarily independent. In addition, if a criterion contains additional subcriteria, there would be a stronger possibility of correlation among subcriteria. Unlike the traditional MCDM methods which often assume independence among criteria and additive importance weights, the nonadditive fuzzy integral is a more effective approach to solve the dependency among criteria, vagueness in information, and essential fuzziness of human judgment.

In terms of managerial implications, this research provides insights for decision makers in both semiconductor manufacturing and 3PL companies. For the semiconductor manufacturing companies with global supply chain and logistics outsourcing needs, this research result provides them with perceivable and holistic information so that they can easily focus on the most important 3PL selection criteria. For the 3PL companies aiming to persist in competitive advantage in the high-tech industries, this research enlightens them that the superior performance, satisfying customer services, and detailed cost-control conform most to the semiconductor manufacturers' requirements. Additionally, although this research is based on a sample of the semiconductor manufacturing industry, the experience of selecting $3 \mathrm{PL}$ providers uncovered in this research could be a valuable reference for other industries with similar characteristics of global supply chain complex, heavy capital investment, short product life cycle, and dynamic market demands.

The main contributions of this study are that it presents a comprehensive 3PL supplier selection's decision framework and produces the importance weights of each selection criterion by considering the interdependent relationship among those selection criteria and eliminating the ambiguous and imprecise nature embedded in decision-makers' subjective 
judgments. The research result can become a valuable reference for manufacturing companies operating in comparable situations. Moreover, the systematic framework presented in this study can be easily extended to the analysis of other decision-making domains.

\section{Conflict of Interests}

The authors declare that there is no conflict of interests regarding the publication of this paper.

\section{Acknowledgments}

This research is supported by the National Science Council, Taiwan (Project no. NSC101-2410-H-224-040-). The authors would also like to thank the reviewers for their constructive comments to improve the overall quality of this paper.

\section{References}

[1] T. Skjoett-Larsen, "Third party logistics-from an interorganizational point of view," International Journal of Physical Distribution and Logistics Management, vol. 30, no. 2, pp. 112127, 2000.

[2] M. Knemeyer, T. M. Corsi, and P. R. Murphy, "Logistics outsourcing relationships: customer perspectives," Journal of Business Logistics, vol. 24, no. 1, pp. 77-109, 2003.

[3] Z. G. Zacharia, N. R. Sanders, and N. W. Nix, "The emerging role of the third-party logistics provider (3PL) as an orchestrator," Journal of Business Logistics, vol. 32, no. 1, pp. 40-54, 2011.

[4] R. Lasch and C. G. Janker, "Supplier selection and controlling using multivariate analysis," International Journal of Physical Distribution and Logistics Management, vol. 35, no. 6, pp. 409425, 2005.

[5] K. Goffin, F. Lemke, and M. Szwejczewski, "An exploratory study of 'close' supplier-manufacturer relationships," Journal of Operations Management, vol. 24, no. 2, pp. 189-209, 2006.

[6] D. A. Carrera and R. V. Mayorga, "Supply chain management: a modular Fuzzy Inference System approach in supplier selection for new product development," Journal of Intelligent Manufacturing, vol. 19, no. 1, pp. 1-12, 2008.

[7] J. L. Yang, H. N. Chiu, G.-H. Tzeng, and R. H. Yeh, "Vendor selection by integrated fuzzy MCDM techniques with independent and interdependent relationships," Information Sciences, vol. 178, no. 21, pp. 4166-4183, 2008.

[8] W. Ho, X. Xu, and P. K. Dey, "Multi-criteria decision making approaches for supplier evaluation and selection: a literature review," European Journal of Operational Research, vol. 202, no. 1, pp. 16-24, 2010.

[9] Z. Wang, K. Leung, and J. Wang, "A genetic algorithm for determining nonadditive set functions in information fusion," Fuzzy Sets and Systems, vol. 102, no. 3, pp. 463-469, 1999.

[10] M. Grabisch, "Fuzzy integral in multicriteria decision making," Fuzzy Sets and Systems, vol. 69, no. 3, pp. 279-298, 1995.

[11] J. H. Chiang, "Choquet fuzzy integral-based hierarchical networks for decision analysis," IEEE Transactions on Fuzzy Systems, vol. 7, no. 1, pp. 63-71, 1999.

[12] R. Lieb and B. A. Bentz, "The use of third-party logistics services by large American manufacturers: the 2004 survey," Transportation Journal, vol. 44, no. 2, pp. 5-15, 2005.
[13] L. Jiang, Y. Wang, and X. Yan, "Decision and coordination in a competing retail channel involving a third-party logistics provider," Computers \& Industrial Engineering, vol. 76, pp. 109121,2014

[14] A. Ç. Suyabatmaz, F. T. Altekin, and G. Şahin, "Hybrid simulation-analytical modeling approaches for the reverse logistics network design of a third-party logistics provider," Computers \& Industrial Engineering, vol. 70, no. 1, pp. 74-89, 2014.

[15] S. Hertz and M. Alfredsson, "Strategic development of third party logistics providers," Industrial Marketing Management, vol. 32, no. 2, pp. 139-149, 2003.

[16] M. J. Maloni and C. R. Carter, "Opportunities for research in third-party logistics," Transportation Journal, vol. 45, no. 2, pp. 23-38, 2006.

[17] S. Jharkharia and R. Shankar, "Selection of logistics service provider: an analytic network process ANP approach," Omega, vol. 35, no. 3, pp. 274-289, 2007.

[18] T. Solakivi, J. Töyli, and L. Ojala, "Logistics outsourcing, its motives and the level of logistics costs in manufacturing and trading companies operating in Finland," Production Planning and Control, vol. 24, no. 4-5, pp. 388-398, 2013.

[19] W. Liu, H. Xu, X. Sun, Y. Yang, and Y. Mo, "Order allocation research of logistics service supply chain with mass customization logistics service," Mathematical Problems in Engineering, vol. 2013, Article ID 957260, 13 pages, 2013.

[20] R. Leuschner, C. R. Carter, T. J. Goldsby, and Z. S. Rogers, "Third-party logistics: a meta-analytic review and investigation of its impact on performance," Journal of Supply Chain Management, vol. 50, no. 1, pp. 21-43, 2014.

[21] A. H. Bask, "Relationships among TPL providers and members of supply chains-a strategic perspective," Journal of Business \& Industrial Marketing, vol. 16, no. 6-7, pp. 471-486, 2001.

[22] R. Wilding and R. Juriado, "Customer perceptions on logistics outsourcing in the European consumer goods industry," International Journal of Physical Distribution and Logistics Management, vol. 34, no. 8, pp. 628-644, 2004.

[23] B. Baki and I. M. Ar, "A comparative analysis of 3PL applications in manufacturing firms from seven countries," Supply Chain Forum, vol. 10, no. 1, pp. 16-30, 2009.

[24] G. Busch, "New twist on supplier evaluation," Purchasing, vol. 55, pp. 102-103, 1962.

[25] G. W. Dickson, "An analysis of vendor selection systems and decisions," Journal of Purchasing, vol. 2, no. 1, pp. 5-17, 1966.

[26] T. R. Coltman, T. M. Devinney, and B. W. Keating, "Best-worst scaling approach to predict customer choice for 3PL services," Journal of Business Logistics, vol. 32, no. 2, pp. 139-152, 2011.

[27] P. R. Murphy and R. F. Poist, "Third-party logistics: some user versus provider perspectives," Journal of Business Logistics, vol. 21, no. 1, pp. 121-133, 2000.

[28] K. D. Gotzamani, P. Longinidis, and F. Vouzas, "The logistics services outsourcing dilemma: quality management and financial performance perspectives," Supply Chain Management, vol. 15, no. 6, pp. 438-453, 2010.

[29] Y. M. Chen, M.-J. Goan, and P.-N. Huang, "Selection process in logistics outsourcing-a view from third party logistics provider," Production Planning and Control, vol. 22, no. 3, pp. 308-324, 2011.

[30] C.-Y. Ku, C.-T. Chang, and H.-P. Ho, "Global supplier selection using fuzzy analytic hierarchy process and fuzzy goal programming," Quality and Quantity, vol. 44, no. 4, pp. 623-640, 2010. 
[31] H. H. Wu and Y. N. Tsai, "Using AHP to evaluate the criteria of auto spare parts industry," Quality \& Quantity, vol. 45, no. 1, pp. 969-983, 2011.

[32] K. Govindan, J. Sarkis, and M. Palaniappan, "An analytic network process-based multicriteria decision making model for a reverse supply chain," The International Journal of Advanced Manufacturing Technology, vol. 68, no. 1-4, pp. 863-880, 2013.

[33] H.-Y. Kang, A. H. I. Lee, and C.-Y. Yang, "A fuzzy ANP model for supplier selection as applied to IC packaging," Journal of Intelligent Manufacturing, vol. 23, no. 5, pp. 1477-1488, 2012.

[34] G. Vaidyanathan, "A Framework for evaluating third-party logistics," Communications of the ACM, vol. 48, no. 1, pp. 8994, 2005.

[35] R. F. Sean, "A new model for selecting third-party reverse logistics providers in the presence of multiple dual-role factors," The International Journal of Advanced Manufacturing Technology, vol. 46, no. 1-4, pp. 405-410, 2010.

[36] S.-H. Chen, "Global production networks and information technology: the case of Taiwan," Industry and Innovation, vol. 9, no. 3, pp. 249-266, 2002.

[37] ITRI, Taiwan Semiconductor Industry Yearbook, Industrial Economics \& Knowledge Center, Taipei, Taiwan, 2011.

[38] H. Göl and B. Çatay, "Third-party logistics provider selection: insights from a Turkish automotive company," Supply Chain Management, vol. 12, no. 6, pp. 379-384, 2007.

[39] S. Jharkharia and R. Shankar, "Selection of logistics service provider: an analytic network process (ANP) approach," The International Journal of Management Sciences, vol. 35, no. 3, pp. 274-289, 2007.

[40] S. M. Ordoobadi, "Development of a supplier selection model using fuzzy logic," Supply Chain Management, vol. 14, no. 4, pp. 314-327, 2009.

[41] E. Bottani and A. Rizzi, "A fuzzy TOPSIS methodology to support outsourcing of logistics services," Supply Chain Management, vol. 11, no. 4, pp. 294-308, 2006.

[42] G. J. Sheen and C. T. Tai, "A study on decision factors and third party selection criterion of logistics outsourcing: an exploratory study of direct selling industry," Journal of American Academy of Business, vol. 9, no. 2, pp. 331-337, 2006.

[43] T. U. Daim, A. Udbye, and A. Balasubramanian, "Use of analytic hierarchy process AHP for selection of 3PL providers," Journal of Manufacturing Technology Management, vol. 24, no. 1, pp. 2851, 2013.

[44] K. Selviaridis and M. Spring, "Third party logistics: a literature review and research agenda," International Journal of Logistics Management, vol. 18, no. 1, pp. 125-150, 2007.

[45] M. A. McGinnis, "A comparative evaluation of freight transportation models," Transportation Journal, vol. 29, no. 2, pp. 3646, 1989.

[46] B.-N. Hwang, S.-C. Chang, H.-C. Yu, and C.-W. Chang, "Pioneering e-supply chain integration in semiconductor industry: a case study," International Journal of Advanced Manufacturing Technology, vol. 36, no. 7-8, pp. 825-832, 2008.

[47] J.-P. Brans and P. Vincke, "A preference ranking organization method," Management Science, vol. 31, no. 6, pp. 647-656, 1985.

[48] R. L. Nydick and R. P. Hill, "Using the analytic hierarchy process to the supplier selection problem," Journal of Purchasing and Materials Management, vol. 28, pp. 31-36, 1992.

[49] S. H. Ghodsypour and C. O’Brien, "A decision support system for supplier selection using an integrated analytic hierarchy process and linear programming," International Journal of Production Economics, vol. 56-57, no. 20, pp. 199-212, 1998.
[50] Z. Li, W. K. Wong, and C. K. Kwong, "An integrated model of material supplier selection and order allocation using fuzzy extended AHP and multiobjective programming," Mathematical Problems in Engineering, vol. 2013, Article ID 363718, 14 pages, 2013.

[51] C.-M. Wu, C.-L. Hsieh, and K.-L. Chang, "A hybrid multiple criteria decision making model for supplier selection," Mathematical Problems in Engineering, vol. 2013, Article ID 324283, 8 pages, 2013.

[52] R. Verma and M. E. Pullman, "An analysis of the supplier selection process," Omega, vol. 26, no. 6, pp. 739-750, 1998.

[53] Z. Degraeve, E. Labro, and F. Roodhooft, "Evaluation of vendor selection models from a total cost of ownership perspective," European Journal of Operational Research, vol. 125, no. 1, pp. 34$58,2000$.

[54] C.-W. Tsui and U.-P. Wen, "A hybrid multiple criteria group decision-making approach for green supplier selection in the TFT-LCD industry," Mathematical Problems in Engineering, vol. 2014, Article ID 709872, 13 pages, 2014.

[55] C. A. Weber, J. R. Current, and A. Desai, "An optimization approach to determining the number of vendors to employ," Supply Chain Management, vol. 5, no. 2, pp. 90-98, 2000.

[56] R. Narasimhan, S. Talluri, and D. Mendez, "Supplier evaluation and rationalization via data envelopment analysis: an empirical example," The Journal of Supply Chain Management, vol. 37, no. 3, pp. 28-37, 2001.

[57] G.-H. Tzeng, Y.-P. Ou Yang, C.-T. Lin, and C.-B. Chen, "Hierarchical MADM with fuzzy integral for evaluating enterprise intranet web sites," Information Sciences, vol. 169, no. 3-4, pp. 409-426, 2005.

[58] J. J. H. Liou and G.-H. Tzeng, "Comments on 'Multiple criteria decision making (MCDM) methods in economics: an overview"' Technological and Economic Development of Economy, vol. 18, no. 4, pp. 672-695, 2012.

[59] Y. C. Kuo, S. T. Lu, G. H. Tzeng, Y. C. Lin, and Y. S. Huang, "Using fuzzy integral approach to enhance site selection assessment-a case study of the optoelectronics industry," Procedia Computer Science, vol. 17, pp. 306-313, 2013.

[60] C.-S. Lai, H.-L. Lee, and Y.-C. Pan, "Applying fuzzy multicriteria decision-making model to ecotour plan selection," Quality \& Quantity, vol. 47, no. 2, pp. 1125-1141, 2013.

[61] M. Sugeno, Theory of Fuzzy Integrals and Its Applications, Tokyo Institute of Technology, Tokyo, Japan, 1974.

[62] R. E. Bellman and L. A. Zadeh, "Decision-making in a fuzzy environment," Management Science, vol. 17, pp. B141-B164, 1970.

[63] C.-H. Wang, I.-Y. Lu, and C.-B. Chen, "Integrating hierarchical balanced scorecard with non-additive fuzzy integral for evaluating high technology firm performance," International Journal of Production Economics, vol. 128, no. 1, pp. 413-426, 2010.

[64] M. Grabisch, "Fuzzy integral as a flexible and interpretable tool of aggregation," in Aggregation and Fusion of Imperfect Information, vol. 12, pp. 51-72, Physica, Heidelberg, Germany, 1998.

[65] M. Sugeno and S. H. Kwon, "A clusterwise regression type model for subjective evaluation," Journal of Japan Society for Fuzzy Theory and Systems, vol. 7, pp. 291-310, 1995.

[66] L. A. Zadeh, "The concept of a linguistic variable and its application to approximate reasoning," Information Sciences, vol. 8, no. 3, pp. 199-249, 1975.

[67] L. A. Shah, A. Etienne, A. Siadat, and F. Vernadat, "Decisionmaking in the manufacturing environment using a value-risk graph," Journal of Intelligent Manufacturing, 2014. 
[68] Y.-W. Chen and G.-H. Tseng, "Using fuzzy integral for evaluating subjectively perceived travel costs in a traffic assignment model," European Journal of Operational Research, vol. 130, no. 3, pp. 653-664, 2001.

[69] G. Büyüközkan, O. Feyzioğlu, and M. Şakir Ersoy, "Evaluation of 4PL operating models: a decision making approach based on 2-additive Choquet integral," International Journal of Production Economics, vol. 121, no. 1, pp. 112-120, 2009.

[70] T. Demirel, N. Ç. Demirel, and C. Kahraman, "Multi-criteria warehouse location selection using Choquet integral," Expert Systems with Applications, vol. 37, no. 5, pp. 3943-3952, 2010.

[71] R. Florez-Lopez, "Strategic supplier selection in the added-value perspective: a CI approach," Information Sciences, vol. 177, no. 5, pp. 1169-1179, 2007.

[72] S.-J. Chen and C.-L. Hwang, Fuzzy Multiple Attribute Decision Making Methods and Applications, Springer, Berlin, Germany, 1992.

[73] M.-L. Tseng, J. H. Chiang, and L. W. Lan, "Selection of optimal supplier in supply chain management strategy with analytic network process and choquet integral," Computers \& Industrial Engineering, vol. 57, no. 1, pp. 330-340, 2009.

[74] H.-K. Chiou and G.-H. Tzeng, "Fuzzy multiple-criteria decision-making approach for industrial green engineering," Environmental Management, vol. 30, no. 6, pp. 816-830, 2002.

[75] G. Büyüközkan and D. Ruan, "Choquet integral based aggregation approach to software development risk assessment," Information Sciences, vol. 180, no. 3, pp. 441-451, 2010.

[76] W. T. Lin, S. C. Chen, H. F. Jang, and H. H. Wu, "Performance evaluation of introducing QS-9000 to the Taiwanese semiconductor industry," International Journal of Advanced Manufacturing Technology, vol. 27, no. 9-10, pp. 1011-1020, 2006.

[77] H.-K. Chiou, G.-H. Tzeng, and D.-C. Cheng, "Evaluating sustainable fishing development strategies using fuzzy MCDM approach," Omega, vol. 33, no. 3, pp. 223-234, 2005.

[78] F.-M. Tseng and Y.-J. Chiu, "Hierarchical fuzzy integral stated preference method for Taiwan's broadband service market," Omega, vol. 33, no. 1, pp. 55-64, 2005.

[79] C.-H. Wang, I.-Y. Lu, and C.-B. Chen, "Evaluating firm technological innovation capability under uncertainty," Technovation, vol. 28, no. 6, pp. 349-363, 2008.

[80] D. Dubois and H. Prade, Fuzzy Sets and Systems: Theory and Applications, Academic Press, New York, NY, USA, 1980.

[81] C. B. Chen and C. M. Klein, "An efficient approach to solving fuzzy MADM problem," Fuzzy Sets and Systems, vol. 88, no. 1, pp. 51-67, 1997.

[82] M. Sugeno and T. Terano, "A model of learning based on fuzzy information," Kybernetes, vol. 6, no. 3, pp. 157-166, 1977.

[83] G. J. Klir, Z. Wang, and D. Harmanec, "Constructing fuzzy measures in expert systems," Fuzzy Sets and Systems, vol. 92, no. 2, pp. 251-264, 1997.

[84] R. L. Keeney and H. Raiffa, Decisions with Multiple Objectives: Preferences and Value Tradeoffs, Wiley, New York, NY, USA, 1976.

[85] K. Leszczyński, P. Penczek, and W. Grochulski, "Sugeno’s fuzzy measure and fuzzy clustering," Fuzzy Sets and Systems, vol. 15, no. 2, pp. 147-158, 1985.

[86] P. M. Byrne, "Cross-border trade: redefining high performance," Logistics Management, vol. 44, no. 3, pp. 25-27, 2005.

[87] H. Gao, L. Xu, C. Li, A. Shi, F. Huang, and Z. Ma, "A new feature selection method for hyperspectral image classification based on simulated annealing genetic algorithm and choquet fuzzy integral," Mathematical Problems in Engineering, vol. 2013, Article ID 537268, 13 pages, 2013. 


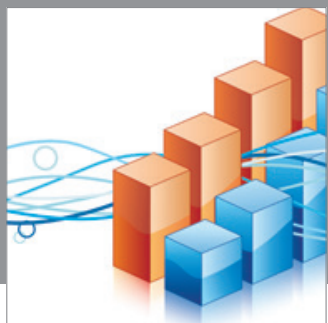

Advances in

Operations Research

mansans

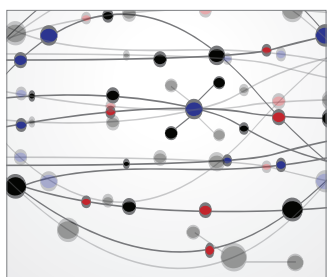

The Scientific World Journal
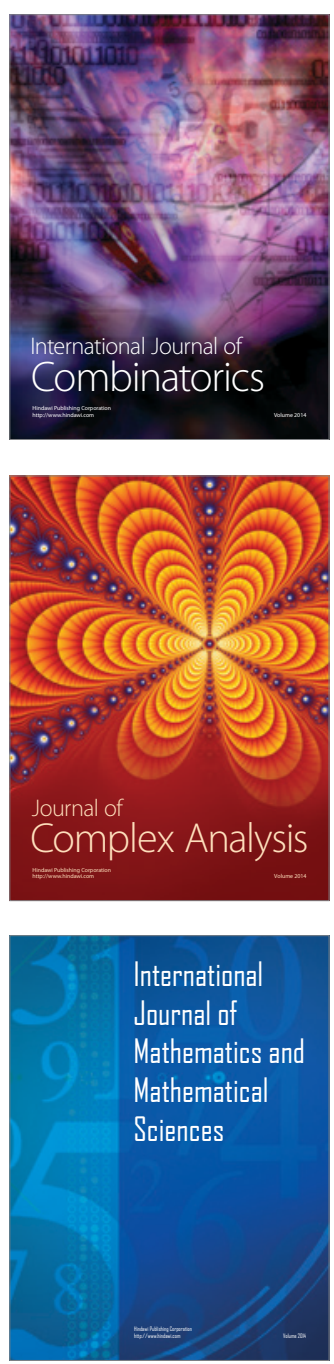
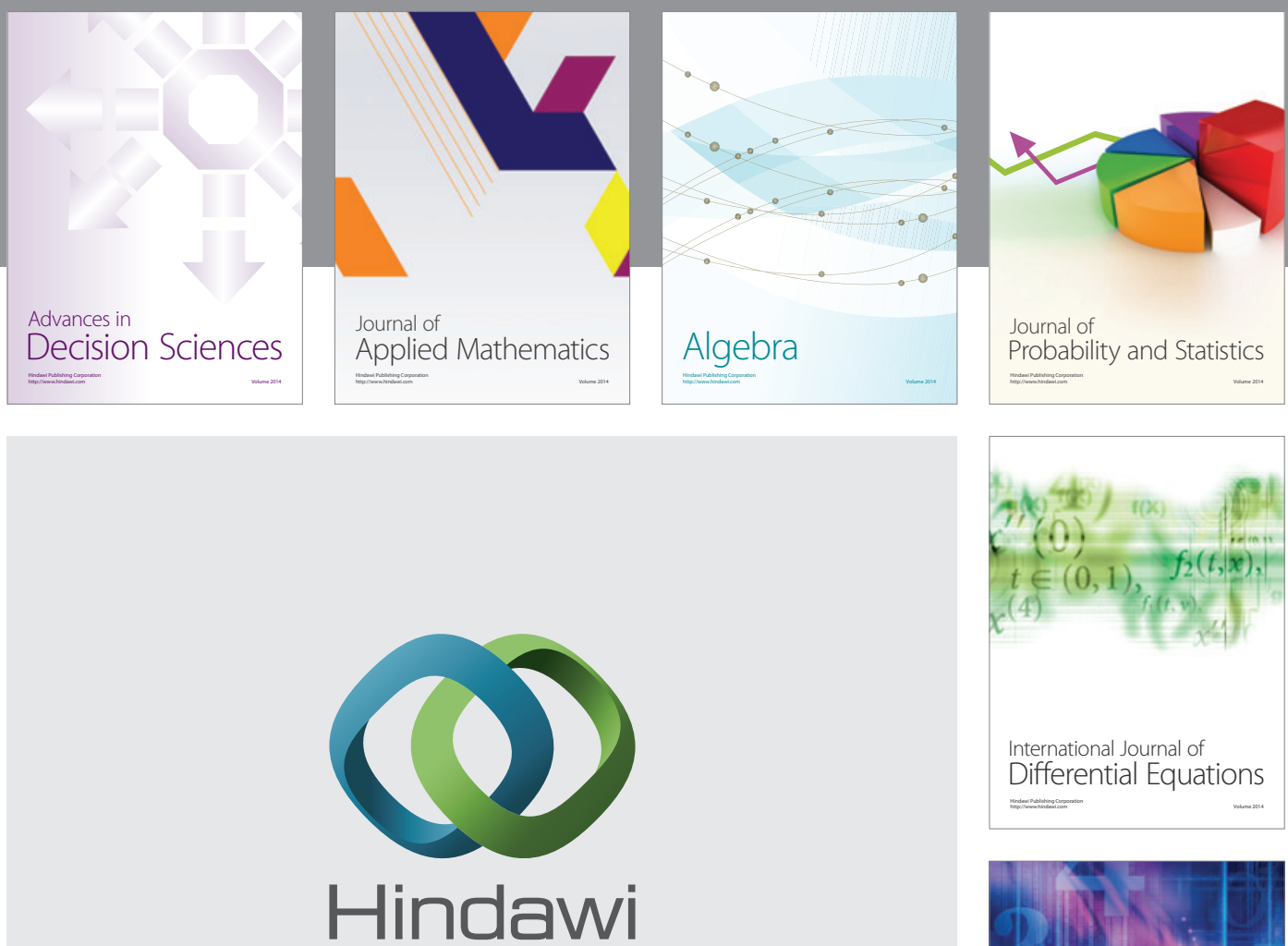

Submit your manuscripts at http://www.hindawi.com
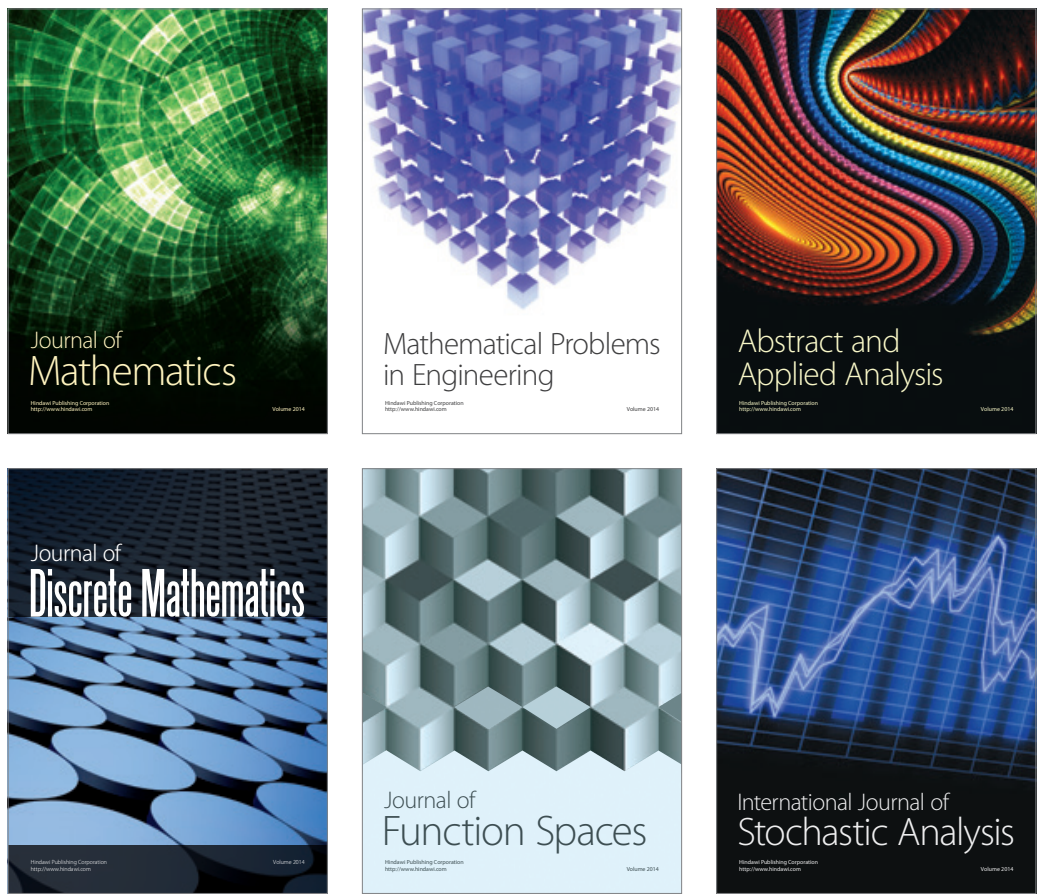

Journal of

Function Spaces

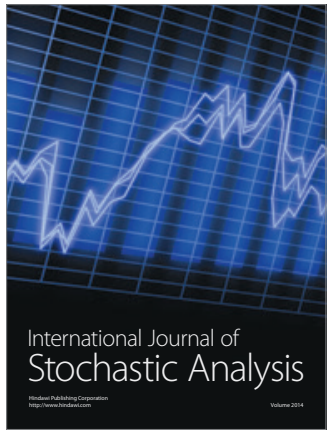

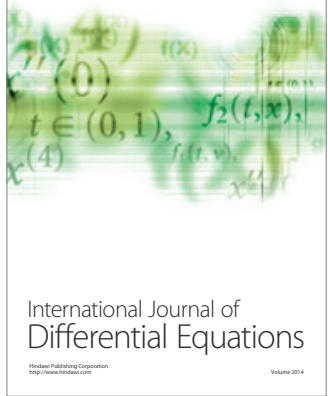
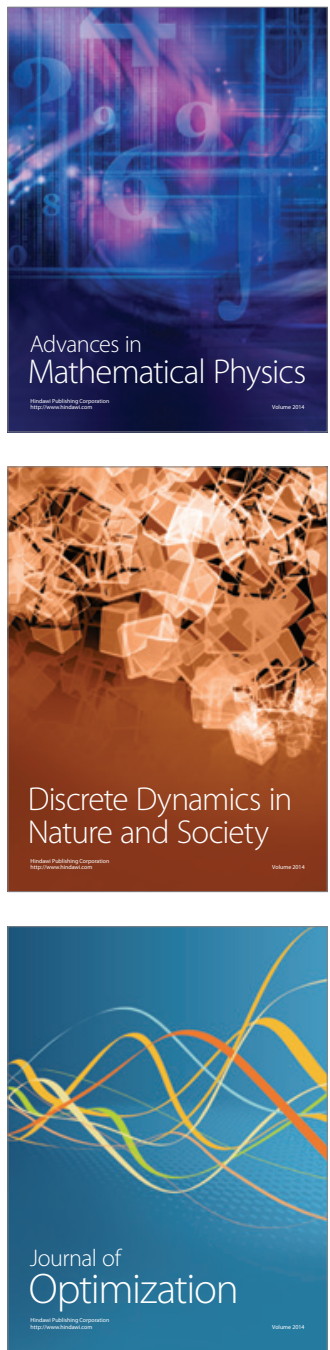